\title{
Towards a Better Understanding of the Value of Block- chains in Supply Chain Management
}

\author{
Michael Lustenberger*, Florian Spychiger, and Sasa Malesevic \\ Zurich University of Applied Sciences, Winterthur, Switzerland \\ \{luse, spyc, malv\}@zhaw.ch
}

\begin{abstract}
Whether or not blockchain technology adds value to supply chains is a highly controversial topic. It has been lauded as the technology that brings transparency and efficiency to supply chains. However, others find this view overly optimistic. In this paper, we aim to add more insight into the issue by applying an action design research approach. We develop and evaluate two artifacts in collaboration with companies and use the results to conclude how blockchain technology can help overcome issues in the current supply chain information flow. It shows that blockchains can provide a shared trust base and a common standard that allows for increased information exchange between supply chain partners. Based on our findings, we propose a research agenda for studying blockchain technology with a stronger focus on governance mechanism and transparency issues.
\end{abstract}

Keywords: Blockchain · Supply chain · Information flow · Governance ·

Transparency

\section{Introduction}

Supply chain management (SCM) explores inter-organizational relationships and the coordination of processes and activities between organizations to improve their performance [1]. Despite the term "supply chain", such relationships are, in reality, non-linear and have a complex network structure [2]. Based on extensive research, there is strong evidence that enhanced coordination and integration within such supply chain networks positively correlates with higher performance by all network members [3, 4]. A particularly important enabler for tight coordination among supply chain partners is the network-wide integration of the information flow [5, 6].

In recent years, blockchain has emerged as a new technology with the potential to integrate and improve the information flow along supply chains significantly $[7,8]$. The identified benefits of this technology in SCM are manifold and include enhanced identity management for assets and individuals [9], the avoidance of inefficient intermediaries [10], increased product traceability [11], and an immutable, secure audit trail [12]. However, as blockchain is a new phenomenon, the benefits of this new technology in SCM is the subject of much discussion among theorists as well as practitioners $[13,14$, 15]. Although some large companies such as Kühne+Nagel [16] and Carrefour [17] 
have started to experiment with blockchain-based applications in their supply chains, there remains a lack of understanding about how blockchain technology can help overcome issues in the current supply chain information flow in practice (see [18]).

To gain greater insight into this topic and to understand better the value of blockchains for SCM, we developed two blockchain-based artifacts for a food label and a pharma supply chain of two companies to address the following research question:

Can blockchain technology help overcome issues in the current information flow for supply chain networks?

The contributions of this study are two-fold. First, we present the experience gained from two practice-use cases. Second, based on the outcome of the two real-world cases, we derive a research agenda for further studies about the value of blockchain for supply chain networks.

The remainder of the paper is structured as follows: In the related work section, we review the existing literature to elaborate on issues in the current information flow for supply chain networks as well as on blockchain technology and its applications in supply chains. In the next section, research method, we describe our research design. In results, we introduce the two case studies by formulating the problem and presenting insights generated by the implementation of the two artifacts, while in the discussion, we reflect on the findings and formalize what we have learned. Finally, in the conclusion, we summarize our results.

\section{$2 \quad$ Related Work}

\subsection{Issues in the Current Supply Chain Information Flow}

The advent of new information system technologies has greatly facilitated the exchange of information in supply chains [5], [19]. Nevertheless, the new technological possibilities are not exhausted, and many companies are less involved than one would expect [20]. Supply chain players need to acquire information technology skills to utilize the full potential of these new systems successfully [21]. At the same time, a mutual willingness to share information requires trust between supply chain partners [22]. However, supply chain networks are shaped by power and information asymmetries [23] as well as diverging interests [5]. Research shows that the more hierarchic and centralized the structure, the more difficult it is to establish that necessary trust [24]. As a result, many companies are still not willing to share data with their supply chain partners.

Without shared standards and a basis of trust, supply chain networks suffer from several issues in their information flows [5], [22]. First, there is an insufficient exchange of information among supply chain partners. As a result, upstream or downstream visibility is limited, and the tracing of goods within the supply chain is complicated. Second, no unique data truth exists in the supply chain, which makes auditing a tedious task. Third, if company information systems are not integrated, processes involving 
several parties are hard to automate. Fourth, the lack of connectedness leads to the inclusion of countless intermediaries functioning solely as information brokers.

\subsection{Blockchains}

The blockchain is an emergent technology initially developed for the digital cash system Bitcoin [25]. Subsequently, the technology has been further developed to register and transact any digital asset as well as to store "smart contracts" and to carry out processes in a distributed manner when all predefined conditions have been fulfilled [26, 27]. These second-generation blockchains can be understood as a "general-purpose programmable infrastructure with a public ledger that records the computational results" [28, p. 244], and they offer four essential qualities that are extremely valuable for applications in SCM [29], [30]:

1) Immutability: Once the data is stored on a blockchain ledger, entries cannot be altered due to a cryptographic hash chain.

2) Transparency: Since each participant stores a copy of the ledger locally, every transaction history is visible.

3) Decentralization: Participants agree on a single truth using a consensus mechanism. No central authority is needed.

4) Process automation: Smart contracts can be deployed to automate secure business processes involving several parties.

This immutable, transparent, and autonomous peer-to-peer processing and storing of data is based on the decentralized structure of blockchains. By decentralizing all protocols and functions, blockchains avoid the need for a central authority to operate and develop the network system. This shift from a centralized to decentralized information technology (IT) system implies a change from trusting in a single network owner to trusting in the shared protocols of the blockchain network. Therefore, it seems plausible from a theoretical perspective to assume that the lack of trust, traditional power structures, and information asymmetries in supply chains mentioned above might be overcome by the introduction of decentralized blockchain-based IT systems. Moreover, by creating a shared IT infrastructure based on mutual trust, it should - theoretically at least - be possible to address current supply chain issues such as visibility, auditability, automation, and intermediaries.

\subsection{Blockchain Application in SCM}

There has been a lot of research in the area of SCM and blockchain, mainly discussing the optimization of supply chains through blockchain technology. Research has been most active in the fields of supply chain finance, SCM information, and supply chain traceability, where the last accounts for more than $40 \%$ of total research [31]. 
An attempt to review the literature on applications systematically suggests five usecase clusters of blockchain-based applications in SCM [32]: visibility, integrity, orchestration, virtualization, and finance. The review concludes that, currently, the main focus of blockchain-based applications is tracing goods and automating supply chain operations. The authors of another review suggest extended visibility and traceability, supply chain digitalization and disintermediation, improved data security, and smart contracts as being the value generators of blockchain technology for SCM [33]. They also suggest that the pharmaceutical and food industries are the most promising sectors for implementation.

In another recent study, the impact of blockchain technology in agriculture and food supply chains was investigated [34]. Most projects focus on food safety and integrity, as well as better supervision and support for small farmers. Although some benefits of using blockchain technology in food supply chains seem apparent - such as tackling unfair pricing, facilitating trade, and monitoring social and environmental responsibility - there are also specific issues. First, blockchain is not sufficiently accessible to all the participants in a network; second, the permanent tracking of goods might raise privacy concerns; and third, blockchain technology is not yet mature enough for utilization in daily operations.

A review of the current research regarding blockchain applications and the biomedical domain shows that scientific literature focuses mainly on integration, integrity, and access control of health records [35]. The authors of the review state that the field is still not well explored and note that within the scope of their investigation, only one study presented a real-world scenario. The implementation process of blockchain projects faces numerous challenges, and network adoption is only possible if a critical mass of stakeholder engagement can be achieved [36]. The lack of standards and governance models [36], as well as incentivization misalignments, represent the most significant issues [37], reported also in the normative literature [38, 39].

To overcome such challenges, [40] proposes an implementation strategy, where only a small number of participants adopt blockchain technology and demonstrate its value by using real-life examples. However, due to a lack of successful real-life implementations, the evidence provided in the literature for the theoretically claimed benefits and issues of blockchain applications in supply chains remains untested and needs to be explored practically.

\section{$3 \quad$ Research Method}

In order to understand the impact of blockchain technology on supply chain networks, we applied an action design research (ADR) method [41]. ADR allows for the design of an IT artifact embedded in an organizational context. The issues and the proposed solution addressed in this study call for close collaboration with industry requiring continuous examination of the specific organizational setting by intervening and evaluating [41]. 
Any further insight gained should contribute not only to academic discussion but also highlight relevant, practical recommendations for companies attempting to apply blockchain technologies to their supply chain network. In our research design, we followed the four stages of the ADR approach (see Fig. 1).

\begin{tabular}{|c|c|c|c|}
\hline $\begin{array}{l}\text { Stage 1: Problem Formulation } \\
-\quad \text { Recognizing the issues in } \\
\text { current IT solutions based on } \\
\text { the supply chain literature and } \\
\text { theory } \\
-\quad \text { Selection of two companies and } \\
\text { identification of their supply } \\
\text { chain issues }\end{array}$ & \begin{tabular}{|l} 
Stage 2: Artifact Development \\
$-\quad$ Building two blockchain \\
artifacts based on the findings \\
in stage 1 \\
$-\quad$ Continuously enhancing the \\
artifacts based on interventions \\
and evaluations within the \\
research team
\end{tabular} & $\begin{array}{l}\text { Stage 3: Reflection \& Learning } \\
-\quad \text { Reflecting on the impact of } \\
\text { each artifact on the supply } \\
\text { chains in the case studies } \\
- \text { Defining the learnings on the } \\
\text { value of the blockhain } \\
\text { technology for the analyzed } \\
\text { supply chain networks }\end{array}$ & $\begin{array}{l}\text { Stage 4: Formalizing the Learning } \\
-\quad \text { Generalizing the use case- } \\
\text { specific findings from stage } 3 \text { to } \\
\text { formulate hypotheses } \\
-\quad \text { Articulating a research agenda } \\
\text { with specific research questions } \\
\text { on how to generate value with } \\
\text { blockchain applications in SCM }\end{array}$ \\
\hline
\end{tabular}

Fig. 1. The research design includes four adapted stages based on the ADR approach.

In the problem formulation stage, we gathered knowledge on the state-of-the-art as well as issues in the current information flow of supply chains through an extensive literature review [42] by applying the keywords (and combinations thereof) "blockchain", "supply chain management", "supply chain", and "literature review" on several online data portals (Google Scholar, ResearchGate, ScienceDirect). We sent invitations to 800 companies located in Switzerland and selected two of them based on their responses. The two companies chosen operate in the food and pharmaceutical industries respectively, the sectors - according to [33] - most relevant for blockchain applications in SCM. In February 2018, we conducted semi-structured interviews [43] with the two companies to understand better the current problems in their respective supply chain information flow. Between February and May 2018, in the artifact development stage, we developed two different blockchain-based artifacts to address the issues from the previous stage. This process was supported by the entire research team as well as the companies involved. In the reflection \& learning stage, the artifacts were evaluated by the independent blockchain expert group from the Swiss Alliance for Data-Intensive Services on 26 June 2018. This provided a clearer understanding of the value of blockchain technology for the supply chain information flows analyzed. In the final formalizing the learning stage, we generalized our case-specific findings.

\section{$4 \quad$ Results}

\subsection{Problem Formulation}

The first company is a multinational producer of pharmaceuticals and a market leader in a highly competitive environment which requires the continuous optimization of processes. Its current supply chain reaches multiple countries all over the world. During the production process, materials have to go through many different stages until an endproduct is forthcoming.

If the company wants to conduct a proper analysis of the production process, quick access to information about material flows along the entire supply chain is required. Furthermore, each entity creates data which must be communicated to the next party. 
In the company's supply chain, the communication process between two adjacent parties is ordinarily efficient, and the flow of data is present. However, a problem occurs when information from an entity further upstream or downstream is required.

Moreover, the process of tracing the end-product back to its origin presents a significant barrier if an integrated information system does not offer the required transparency. In the highly regulated medical sector, especially, it is mandatory for a company to provide full documentation about the origin and quality of their products. Due to the missing information exchange beyond directly adjacent supply chain players, it is hard to fulfill the regulatory requirements since most of the documentation process is still paper-based and distributed among different systems and operators.

The second company analyzed in this study is an association acting as a food label for numerous regional producers of dairy and meat products. For a label which gives consumers not only the assurance of legal compliance but also of regionally produced, high-quality products, it is crucial to safeguard their credibility. For this reason, independent certification authorities regularly audit each partner to guarantee the label's certified food supply chain. Because of the complexity of this process, several problems in the information flow arise. First, it is difficult to trace a finished meat product back to a specific animal as the identification system is not yet foolproof. Second, to track the entire process, all partners in the food supply chain need to store relevant documentation (often paper-based) for the disclosure of selected product histories on request. This makes the auditing process time-consuming as information is scattered among many supply chain members. Third, coordination of the entire verification process is problematic because each player might use a different database and there is no shared system implying that an auditor has to visit each production site in person every second year to certify the label's requirements. A fourth issue is that owing to a lack of transparency on product level, only supply chain members are certified and not the actual products themselves. 


\subsection{Artifact Development}

The pharma artifact implements a private blockchain-based application built on Hyperledger Fabric whose architecture is shown in Figure 2. The selection of a private blockchain was an essential criterion for the multinational company to maintain full control over access and development of the system as well as to allow for private transactions between its network members. In the application, a predefined membership service manages access rights to a shared information system for all supply chain partners. Once all network partners have access to the system, each step in the supply chain needs

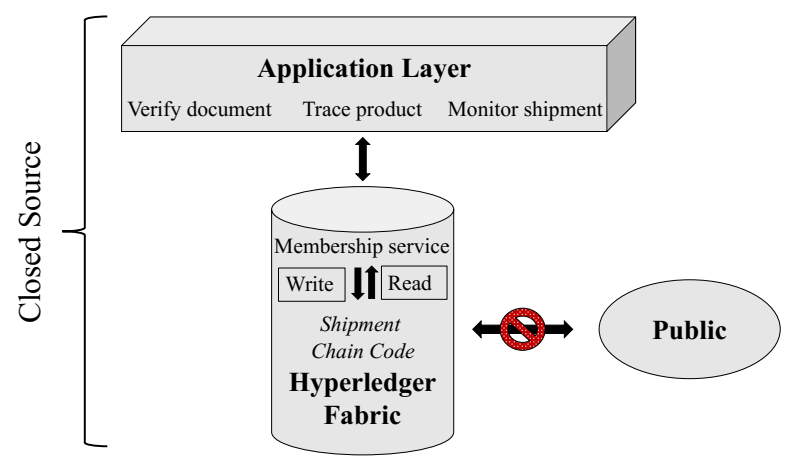

Fig. 2. Architecture of the pharma artifact based on Hyperledger Fabric. Everything is secure and only accessible by authorized members.

to be communicated and validated through the blockchain network. Raw material suppliers register their materials in the blockchain which then can be transferred by transportation companies to the manufacturers. Each manufacturer selects the raw materials required and registers its manufactured products as new assets on the blockchain. Once registered, these new products can be transferred again to the next supply chain partner, who again selects the required materials and registers its newly manufactured products on the blockchain. Ultimately, every stage from raw material supply to finished product is recorded on the blockchain. A regulator or client is, therefore, able to trace the entire history of a product along the supply chain using one system.

In addition to monitoring the flow of tangible goods, the artifact has two further benefits. First, by storing a cryptographic hash of essential documents on the blockchain, users can verify the authenticity of certificates, batch documents, or invoices in a tamper-proof environment. Second, by connecting a Raspberry Pi 3 to the artifact, it is possible to record temperature during transportation and to send the data via mobile communication to the blockchain. Based on the immutable chain codes (smart contracts), shipment conditions can be continuously monitored, and if, for example, a temperature deviates from a predefined range, the application sends an automatic e-mail alert to the shipper and the consignee. 
In contrast to the pharma company, full transparency and less system control were no issue for the small, regional food label. Their network incorporates many small heterogeneous players with non-standardized databases. The label artifact consists, therefore, of a blockchain-based platform that gives everyone in the supply chain network (from the consumer or small farmer to large enterprises) easy access to a documentation system. As shown in Figure 3, the artifact is based on Ethereum, where each partner can use an asset registry contract that creates a new smart contract for each asset (e.g., a cow). This creates an immutable entry for every asset in the system which can be mapped to existing identification systems, e.g., earmarks. Once registered on the blockchain, ownership of the smart contract (asset) can be transferred only by the current owner to a new owner. In this way, the ownership history of the asset is recorded and can be traced. Once the asset arrives at a production site (e.g., the butcher), it can be further processed

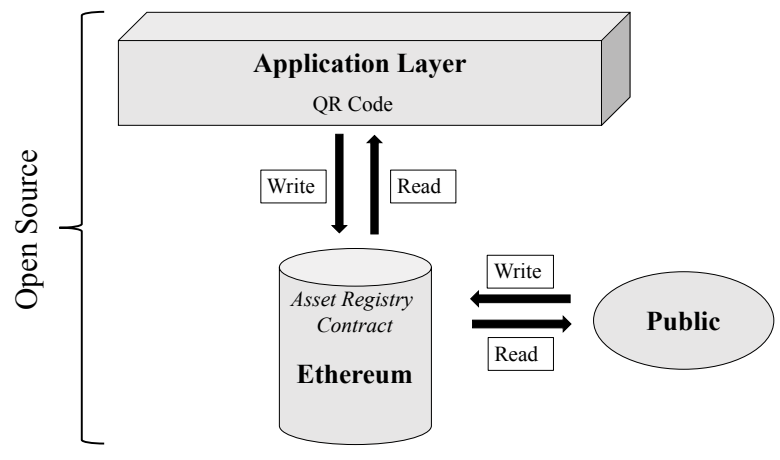

Fig. 3. Pharma artifacts allows everyone to access the asset registry contract stored on the publicly accessible Ethereum blockchain.

into new assets (e.g., steaks) by the new asset owner. For that purpose, the "parent" smart contract creates new "child" assets which, in turn, can be further processed along the supply chain. This processing is equipped with different control-mechanism enforced by the "parent" smart contract; for example, only the owner is allowed to process an asset, and a newly created asset may not have a higher weight than its parent. Such mechanisms allow for plausibility checks along the supply chain. Finally, end-consumers in the supermarket have the option of scanning a QR-code to access the entire supply chain history of their purchase.

\section{Discussion}

\subsection{Reflection \& Learning}

Based on the development and implementation of blockchain-based artifacts in the two supply chains, we suggest that blockchain technology can provide an effective way to improve on multiple issues. 
First, it can tackle the lack of visibility. Specifically, it increases visibility within the supply chain and allows companies to exchange information across the entire network. Further, due to the facilitated exchange of information and the digitization of paperbased processes, there should be an overall increase in the efficiency of daily operations. Second, it improves the auditability of all kind of supply chain processes. In economic sectors confronted with high-quality standards and many legal regulations, it is crucial to offer an immutable audit trail of information. Blockchain-based document verification creates the basis for an efficient, detailed, digital auditing process. This suggests a further opportunity for the label supply chain; it is now possible to create audit trails (and therefore certificates) at product level rather than only at the producer level. Third, blockchain technology allows smart contracts to monitor and enforce agreements between supply chain partners autonomously, for example, by imposing penalties in the case of deviation from a predefined temperature range during transportation. Fourth, based on our observations, we believe that disintermediation is possible. The products from both companies in our study rely on external certification authorities to be checked and verified. By using a blockchain, it is possible to reduce this dependency on external auditors thanks to a shared data system giving authorities and consumers direct access to an immutable audit trail.

Besides the potential for overcoming the identified supply chain issues, our artifacts also revealed some technical limitations. In the publicly accessible Ethereum blockchain, transaction fees can be quite substantial although throughput is rather low. The private Hyperledger Fabric platform improves on this by using a different consensus mechanism resulting in fast transactions and no fees. Due to these technical issues as well as the economic possibilities of the two companies, we were confident that the pharma artifact could be further developed and implemented in the daily operations of the pharma network at a later stage. However, to our surprise, the pharma company abandoned the project entirely in June 2018, whereas the food label association showed interest in developing the artifact further.

\subsection{Formalizing the Learning}

Even though the different reactions from the two companies were difficult to understand initially, we eventually arrived at several new research hypotheses. First, to materialize the advantages of blockchains described in the previous section, it is not sufficient simply to implement the technology, since the technology per se enables only a technological infrastructure. To exploit the full potential of blockchain-based networks, the governance aspects of these decentralized systems [12], as well as standards [36] and incentive structure [37], play a significant role. A shared information system requires a specific set of rules about how to develop the system, who has what rights, and how to integrate new members. The development and implementation of such decentralized blockchain governance are much more difficult in a strongly centralistic and hierarchic supply chain with a high degree of asymmetric power and interest distribution. In contrast, a decentralized network structure - such as the supply chain of the 
food label association - with flat hierarchies and symmetric interest distribution represent a promising initial situation for the successful creation of a governance structure for a shared blockchain system.

Second, the supply chain needs to share a strategic interest to increase its transparency and auditability; the entire business model of the food label association relies on these characteristics. By contrast, a trade-off between efficient information exchange and privacy prevails in many other businesses. As long as companies fear losing out if they disclose information, greater transparency in supply chains will be hard to achieve.

Based on these two hypotheses, we propose a research agenda for future studies. Whereas the normative literature suggests some research directions for blockchain governance [39], our research agenda is clarly motivated by two practical applications. First and most importantly, further studies should focus on governance mechanisms in blockchain-based applications and networks. How can decentralized systems be coordinated? What are the structural pre-requisites for successful blockchain implementation? Second, in most industries, transparency is viewed more as a threat than an asset. It would be interesting to investigate further the "business model" for transparency in traditional companies. How can current business models be modified so that transparency and collaboration become worthwhile goals? What is needed from a business perspective for companies to be willing to invest in the potential benefits of blockchain applications? Third, even though we worked with companies and observed practical applications, it is still necessary to see other such systems operating in real-world situations. Further studies of operational applications are needed to incorporate additional factors from practice into the analysis to understand better the circumstances under which a blockchain-based supply chain application can be successfully implemented.

\section{Conclusion}

In this paper, we have studied the application of blockchain technology in SCM using two developed artifacts. In doing so, we contributed to the literature in two ways:

First, our artifacts show that, depending on the specific application, blockchain technology can overcome supply chain issues such as visibility, auditability, automation, and intermediaries. Common to all blockchain-based applications is an acceleration of digitization due to the need for a shared and trusted IT infrastructure in the supply chain network. These findings have enabled us to answer our research question ("Can blockchain technology help overcome issues in the current information flow for supply chain networks?") in the affirmative.

Second, as a result of our artifacts, we could see that blockchains are only beneficial if they are implemented in a supply chain which has already a decentralized organization, and a business strategy that supports transparency and auditability. Without that premise, it is a challenge to tackle the incentive and governance issues arising from blockchain technology. In our case, only the food label supply chain already offers the prerequisite decentralized structure with the result that only this case will be developed further. 
Consequently, we expand on the normative literature and propose a research agenda motivated by two real-world use cases for studying blockchain technology in SCM with a stronger focus on governance mechanism and transparency issues in blockchainbased networks and applications. Additionally, more real-world implementations of blockchain-based supply chain solutions need to be studied to create further insight into where and when this new technology can be successfully implemented.

\section{$7 \quad$ References}

1. Cooper, M.C.: Supply Chain Management: More Than a New Name for Logistics. The International Journal of Logistics Management. 8, 1, 1-14 (1997). https://doi.org/10.1108/09574099710805556.

2. Choi, T.Y., Kim, Y.: Structural Embeddedness and Supplier Management: A Network Perspective. Journal of Supply Chain Management. 44, 4, 5-13 (2008). https://doi.org/10.1111/j.1745-493X.2008.00069.x.

3. Frohlich, M.T., Westbrook, R.: Arcs of integration: an international study of supply chain strategies. Journal of Operations Management. 19, 2, 185-200 (2001). https://doi.org/10.1016/S0272-6963(00)00055-3.

4. Ataseven, C., Nair, A.: Assessment of supply chain integration and performance relationships: A meta-analytic investigation of the literature. International Journal of Production Economics. 185, 252-265 (2017). https://doi.org/10.1016/j.ijpe.2017.01.007.

5. Lee, H.L., Whang, S.: Information sharing in a supply chain. International Journal of Manu$\begin{array}{lllllll}\text { facturing Technology and Management. } 1, & 1, & 79 & \text { (2000). }\end{array}$ https://doi.org/10.1504/IJMTM.2000.001329.

6. Vanpoucke, E., Vereecke, A., Muylle, S.: Leveraging the impact of supply chain integration through information technology. International Journal of Operations \& Production Management. 37, 4, 510-530 (2017). https://doi.org/10.1108/IJOPM-07-2015-0441.

7. Gunasekaran, A., Ngai, E.W.: Information systems in supply chain integration and management. European Journal of Operational Research. 159, 2, 269-295 (2004). https://doi.org/10.1016/j.ejor.2003.08.016.

8. Casey, M.J., Wong, P.: Global Supply Chains Are About to Get Better, Thanks to Blockchain, https://hbr.org/2017/03/global-supply-chains-are-about-to-get-better-thanks-to-blockchain, (2017).

9. Mainelli, M.: Blockchain Will Help Us Prove Our Identities in a Digital World, https://hbr.org/2017/03/blockchain-will-help-us-prove-our-identities-in-a-digital-world, (2017).

10. Koetsier, J.: Blockchain Beyond Bitcoin: How Blockchain Will Transform Business in 3 to 5 Years, https://www.inc.com/john-koetsier/how-blockchain-will-transform-business-in-3to-5-years.html, (2017).

11. O’Marah, K.: Blockchain: Enormous Potential Demands Your Attention, https://www.supplychaindigital.com/technology/blockchain-enormous-potential-demands-your-attention, (2017). 
12. Kshetri, N.: Blockchain's roles in meeting key supply chain management objectives. International Journal of Information Management. 39, 80-89 (2018). https://doi.org/10.1016/j.ijinfomgt.2017.12.005.

13. Alicke, K., Davies, A., Leopoldseder, M., Niemeyer, A.: Blockchain technology for supply chains - A must or a maybe?, https://www.mckinsey.com/business-functions/operations/ourinsights/blockchain-technology-for-supply-chainsa-must-or-a-maybe, (2017).

14. Wüst, K., Gervais, A.: Do you need a Blockchain? In: 2018 Crypto Valley Conference on Blockchain Technology (CVCBT). pp. 45-54 IEEE (2018).

15. Queiroz, M.M., Teles, R., Bonilla, S.H.: Blockchain and supply chain management integration: a systematic review of the literature. Supply Chain Management: An International Journal. (2019). https://doi.org/10.1108/SCM-03-2018-0143.

16. Schmidt, A.: Kuehne + Nagel deploys blockchain technology for VGM Portal, https://newsroom.kuehne-nagel.com/kuehne--nagel-deploys-blockchain-technology-for-vgm-portal/, (2018).

17. Thomasson, E.: Carrefour says blockchain tracking boosting sales of some products, https://www.reuters.com/article/us-carrefour-blockchain-idUSKCN1T42A5, (2019).

18. Petersen, M., Hackius, N., von See, B.: Mapping the sea of opportunities: Blockchain in supply chain and logistics. it - Information Technology. 60, 5-6, 263-271 (2018). https://doi.org/10.1515/itit-2017-0031.

19. Tapscott, D., Tapscott, A.: Blockchain revolution: how the technology behind bitcoin is changing money, business, and the world. Portfolio/Penguin, New York (2016).

20. Deflorin, P., Hauser, C., Scherrer-Rathje, M.: Schweizer Unternehmen sehen Digitalisierung als Chance. Die Volkswirtschaft. 88, 5, 58-61 (2015).

21. Liu, H., Wei, S., Ke, W., Wei, K.K., Hua, Z.: The configuration between supply chain integration and information technology competency: A resource orchestration perspective. Journal of Operations Management. 44, 1, 13-29 (2016). https://doi.org/10.1016/j.jom.2016.03.009.

22. Fawcett, S.E., Osterhaus, P., Magnan, G.M., Brau, J.C., McCarter, M.W.: Information sharing and supply chain performance: the role of connectivity and willingness. Supply Chain

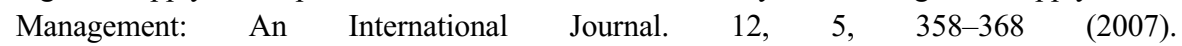
https://doi.org/10.1108/13598540710776935.

23. Cox, A.: The art of the possible: relationship management in power regimes and supply chains. Supply Chain Management: An International Journal. 9, 5, 346-356 (2004). https://doi.org/10.1108/13598540410560739.

24. Capaldo, A., Giannoccaro, I.: How does trust affect performance in the supply chain? The moderating role of interdependence. International Journal of Production Economics. 166, 3649 (2015). https://doi.org/10.1016/j.ijpe.2015.04.008.

25. Nakamoto, S.: Bitcoin: A peer-to-peer electronic cash system. (2008).

26. Wood, G.: Ethereum: A secure decentralised generalised transaction ledger. Ethereum project yellow paper. 151, 2014, 1-32 (2014).

27. Cachin, C.: Architecture of the hyperledger blockchain fabric. In: Workshop on distributed cryptocurrencies and consensus ledgers. p. 4 (2016).

28. Özer, Ö., Zheng, Y.: Establishing Trust and Trustworthiness for Supply Chain Information Sharing. In: Ha, A.Y. and Tang, C.S. (eds.) Handbook of Information Exchange in Supply 
Chain Management. pp. 287-312 Springer International Publishing, Cham (2017). https://doi.org/10.1007/978-3-319-32441-8_14.

29. Xu, X, Weber, I., Staples, M., Zhu, L., Bosch, L., Pautasso, C., Rimba, P.: A Taxonomy of Blockchain-Based Systems for Architecture Design. In: 2017 IEEE International Conference on Software Architecture (ICSA). pp. 243-252 IEEE, Gothenburg, Sweden (2017). https://doi.org/10.1109/ICSA.2017.33.

30. Voshmgir, S.: Blockchains, Smart Contracts und das Dezentrale Web. Technologiestiftung Berlin, Blockchains, Smart Contracts und das Dezentrale Web. 17-35 (2016).

31. Tribis, Y., Weber, I., Staples, M., Zhu, L., Bosch, J., Bass, L., Pautasso, C., Rimba, P.: Supply Chain Management based on Blockchain: A Systematic Mapping Study. MATEC Web of Conferences. 200, 00020 (2018). https://doi.org/10.1051/matecconf/201820000020.

32. Blossey, G., Eisenhardt, J., Hahn, G.: Blockchain Technology in Supply Chain Management: An Application Perspective. Presented at the Hawaii International Conference on System Sciences (2019). https://doi.org/10.24251/HICSS.2019.824.

33. Wang, Y., Han, J.H., Beynon-Davies, P.: Understanding blockchain technology for future supply chains: a systematic literature review and research agenda. Supply Chain Management: An International Journal. 24, 1, 62-84 (2019). https://doi.org/10.1108/SCM-03-2018-0148.

34. Kamilaris, A., Fonts, A., Prenafeta-Boldú, F.C.: The rise of blockchain technology in agriculture and food supply chains. Trends in Food Science \& Technology. 91, 640-652 (2019). https://doi.org/10.1016/j.tifs.2019.07.034.

35. Drosatos, G., Kaldoudi, E.: Blockchain Applications in the Biomedical Domain: A Scoping Review. Computational and Structural Biotechnology Journal. 17, 229-240 (2019). https://doi.org/10.1016/j.csbj.2019.01.010.

36. Dobrovnik, M., Herold, D., Fürst, E., Kummer, S.: Blockchain for and in Logistics: What to Adopt and Where to Start. Logistics. 2, 18 (2018). https://doi.org/10.3390/logistics2030018.

37. Sternberg, H., Baruffaldi, G.: Chains in chains - logic and challenges of blockchains in supply chains. In: 51st Hawaii International Conference on System Sciences. pp. 3936-3943 (2018).

38. Piscini, E.: Why 2017 is Blockchain's Make or Break Year, https://www.coindesk.com/why2017-is-blockchains-make-or-break-year, (2017).

39. Beck, R., Müller-Bloch, C., King, J. L.: Governance in the Blockchain Economy: A Framework and Research Agenda. Journal of the Association for Information Systems. 19, 10,1020 - 1034 (2018). https://doi.org/10.17705/1jais.00518.

40. Sulkowski, A. J.: Blockchain, Business Supply Chains, Sustainability, and Law: The Future of Governance, Legal Frameworks, and Lawyers? Delaware Journal of Corporate Law. 43, 2 , 303 - 345 (2019). http://dx.doi.org/10.2139/ssrn.3205452.

41. Sein, M.K., Henfridsson, O., Purao, S., Rossi, M., Lindgren, R.: Action Design Research. MIS Quarterly. 35, 1, 37 - 56 (2011). https://doi.org/10.2307/23043488.

42. Vom Brocke, J., Simons, A., Niehaves, B., Riemer, K., Plattfaut, R., Cleven, A.: Reconstructing the giant: on the importance of rigour in documenting the literature search process. In: Ecis. pp. 2206-2217 (2009).

43. Myers, M.D., Newman, M.: The qualitative interview in IS research: Examining the craft. Information and Organization. 17, 1, $2-26 \quad$ (2007). https://doi.org/10.1016/j.infoandorg.2006.11.001 